\title{
MEDIA COMPANY PROFILE SEBAGAI SARANA PENUNJANG INFORMASI DAN PROMOSI
}

\author{
Maimunah $^{1}$ \\ Lusyani Sunarya ${ }^{2}$ \\ Nina Larasati ${ }^{3}$ \\ e-mail:maimunah@faculty.raharja.ac.id,lusyani_sunarya@faculty.raharja.ac.id, \\ nina.larasati@mi.raharja.ac.id
}

Diterima : 11 Januari 2012 / Disetujui : 18 Januari 2012

\begin{abstract}
Currently, developments in information technology world and promoting media is growing rapidly, it is marked by numerous public needs that information. Types of supporting media campaign that is currently very varied, it was the demands of the promotional strategy developed by the company to achieve profit for the success of a company. Promotion is one determinant of the success of a marketing program within a company. Currently, media promotions such as anything that can provide information to the public or business entity that can communicate PT. Multi-Technology Innovation is good and interesting, to the audience so that the resulting information can be added value, sales value and whether it the name of the company, as one alternative to solving the problem, it needs a media campaign design an effective form of company profile, attract the attention of all consumers and for entrepreneurs to cooperate. The company profile you want to create it covers all the company's assets include: History Company, Vision and Mission of the Company, Electronic Telephone Billing, Product Excellence, Regional Marketing, business models, corporate activities such as production, participation in exhibitions, collaborative activities with business associates and others.
\end{abstract}

Keywords: Design, Media, Information, Promotion, Company Profile

1. Dosen Jurusan Teknik Informatika, AMIK Raharja Informatika

Jl. Jend Sudirman No. 40 Modern Cikokol-Tangerang Telp. 5529692

2. Dosen Jurusan Teknik Informatika, STMIK Raharja

J1. Jend Sudirman No. 40 Modern Cikokol-Tangerang Telp. 5529692

3. Mahasiswa Jurusan Manajemen Informatika, AMIK Raharja Informatika

Jl. Jend Sudirman No. 40 Modern Cikokol-Tangerang Telp. 5529692

Vol.5 No.3 - Mei 2012 


\section{ABSTRAKSI}

Saat ini perkembangan dalam dunia teknologi informasi dan media promosi berkembang dengan pesat, hal ini ditandai dengan banyaknya kebutuhan masyarakat akan informasi tersebut. Jenis media penunjang promosi yang ada saat ini sangat bervariasi, hal tersebut merupakan tuntutan dari strategi promosi yang dikembangkan oleh perusahaan untuk mencapai profit untuk keberhasilan sebuah perusahaan. Promosi merupakan salah satu penentu keberhasilan suatu program pemasaran dalam suatu perusahaan. Saat ini media promosi seperti apa yang dapat memberikan informasi kepada masyarakat atau pelaku bisnis yang dapat mengkomunikasikan PT. Inovasi Multi Teknologi secara baik dan menarik, kepada khalayak sehingga informasi yang dihasilkan dapat menjadi nilai tambah, nilai jual serta mengharumkan nama baik perusahaan, sebagai salah satu alternatif pemecahan masalah, maka diperlukan sebuah perancangan media promosi berupa Company Profile yang efektif, menarik perhatian seluruh konsumen dan bagi pelaku bisnis untuk melakukan kerjasama. Adapun Company Profile yang ingin dibuat ini mencakup seluruh aset perusahaan diantaranya : Sejarah Perusahaan, Visi dan Misi Perusahaan, Electronic Billing Telephone, Keunggulan Produk, Wilayah Pemasaran, Model bisnis, Kegiatan-kegiatan perusahaan seperti kegiatan produksi, kegiatan dalam keikutsertaan pameran, kegiatan kerjasama dengan relasi bisnis dan lain-lain.

Kata kunci : Perancangan, Media, Informasi, Promosi, Company Profile

\section{PENDAHULUAN}

Saat ini perkembangan dalam dunia teknologi informasi dan media promosi berkembang dengan pesat, hal ini ditandai dengan banyaknya kebutuhan masyarakat akan informasi tersebut. Jenis media promosi yang ada saat ini sangat bervariasi, hal tersebut dikarenakan tuntutan dari strategi promosi yang dikembangkan oleh perusahaan untuk mencapai profit untuk kemajuan sebuah Perusahaan.

Promosi merupakan salah satu penentu keberhasilan suatu program pemasaran dalam suatu perusahaan. Pada hakikatnya promosi adalah suatu bentuk komunikasi pemasaran, yang dimaksud dengan komunikasi pemasaran adalah aktivitas pemasaran yang berusaha menyebarkan informasi, mempengaruhi atau membujuk dan mengingatkan pasar sasaran atas perusahaan dan produknya agar bersedia menerima dan loyal pada produk yang ditawarkan perusahaan yang bersangkutan.

Company Profile adalah sebuah aset suatu lembaga atau perusahaan yang dapat digunakan untuk meningkatkan suatu image atau citra dari perusahaan untuk menjalin kerja sama dengan relasi perusahaan, lembaga dan instansi terkait lainnya. Company Profile tersebut sebagai aset perusahaan yang dipegang dan dimiliki oleh setiap perusahaan atau lembaga. Dimana Company Profile, selain sebagai aset perusahaan juga berfungsi sebagai tanda atau identitas dari perusahaan dalam menjalin kerjasama atau relasi yang baik dengan perusahaan atau lembaga atau instansi terkait 
lainnya. Secara umum Company Profile dibuat dalam bentuk buku yang ditata secara baik dengan menggunakan unsur desain komunikasi visual dengan menggunakan perpaduan unsur bentuk, warna, tipografi serta elemen-elemen estetis pendukung lainnya yang tersusun dalam sebuah tatanan komposisi yang dinamis.

PT. Inovasi Multi Teknologi adalah perusahaan yang bergerak di bidang industri jasa dan manufaktur khususnya komunikasi. Produk yang dihasilkan adalah Electronic Billing Telephone, yaitu sebuah produk pengontrol pemakaian telepon yang memberikan solusi akan efisiensi dan otomatisasi secara elektronik, sehingga dapat melakukan penghematan dan menghindari penyalahgunaan hingga pembatasan maksimal untuk pembayaran telepon.

Dari hasil analisa yang dilakukan oleh penulis terhadap pihak PT. Inovasi Multi Teknologi melalui observasi dan interview terhadap pihak-pihak terkait di perusahaan tersebut, bahwa selama ini PT. Inovasi Multi Teknologi dalam mempromosikan produknya hanya melalui bentuk-bentuk media seperti brosur, pamflet, spanduk dan poster. Belum ada media Company Profile yang bermanfaat bagi perusahan sebagai aset untuk memperkenalkan kapasitas dan kulitas perusahaan dalam menjalin kerjasama atau relasi dengan perusahaan terkait lainnya.

Berdasarkan hal yang disampaikan di atas dan dari hasil interview, bahwa media Company Profile adalah media sarana informasi yang dibutuhkan saat ini yang diharapkan dapat dijadikan solusi sarana informasi dan promosi yang dibutuhkan oleh PT. Inovasi Multi Teknologi

\section{RUMUSAN MASALAH}

Rumusan masalah yang dikemukanakan dalam artikel ini adalah :

a. Media Promosi dan informasi seperti apa yang efektif untuk memperkenalkan kapasitas dan kualitas perusahaan?

b. Bagaimana merancang media Company Profile yang mempunyai nilai daya tarik, meningkatkan image perusahaan dan sekaligus dapat menunjang program promosi?

c. Bagamana menciptakan sebuah media informasi dan promosi yang sesuai dengan citra atau image perusahaan?

\section{TINJAUAN PUSTAKA}

\section{Pengertian Promosi}

Promosi merupakan salah satu penentu keberhasilan suatu program pemasaran. Pentingnya promosi dapat digambarkan lewat perumpamaan bahwa pemasaran tanpa promosi dapat diibaratkan seorang pria berkaca mata hitam yang dari tempat gelap 
pada malam kelam mengedipkan matanya pada seorang gadis dikejauhan. Tak seorang pun yang tahu apa yang dilakukan pria tersebut selain dirinya sendiri.

Pada hakikatnya promosi adalah suatu bentuk komunikasi pemasaran. Yang dimaksud dengan komunikasi pemasaran adalah aktivitas pemasaran yang berusaha menyebarkan informasi, mempengaruhi atau membujuk dan mengingatkan pasar sasaran atas perusahaan dan produknya agar bersedia menerima dan loyal pada produk yang ditawarkan perusahaan yang bersangkutan.

\section{Pengertian Informasi}

Informasi adalah data yang telah diolah menjadi sebuah bentuk yang lebih berarti bagi penerimanya, dan bermanfaat dalam mengambil suatu keputusan. Informasi dapat didefinisikan sebagai hasil dari pengolahan data dalam suatu bentuk yang lebih berguna dan lebih berarti bagi penerimanya yang menggambarkan suatu kejadian-kejadian (event) yang nyata (fact) yang digunakan untuk pengambilan keputusan.

\section{Pengertian Media}

Media adalah sarana untuk menyampaikan pesan atau informasi kepada public dengan menggunakan berbagai unsur komunikasi grafis seperti teks atau gambar/ foto.

Media adalah saluran penyampaian pesan komersial kepada khalayak sasaran atau dapat dikatakan salah satu komunikasi periklanan yang dilakukan melalui saluran media tertentu, seperti televisi, surat kabar, majalah, radio, internet, buku profil, media luar ruang, iklan transit dan direct mail.

Pemilihan setiap media dipengaruhi oleh faktor-faktor seperti ciri produk, jenis pesan, pasar sasaran, luas dan jenis distribusi, anggaran, strategi iklan pesaing, serta keunggulan dan kekurangan media itu sendiri.

\section{Definisi Company Profile}

Company Profile adalah sebuah aset suatu lembaga atau perusahaan yang dapat digunakan untuk meningkatkan suatu image atau citra dari perusahaan untuk menjalin kerja sama dengan relasi perusahaan, lembaga dan instansi terkait lainnya. Company Profile tersebut sebagai aset perusahaan yang dipegang dan dimiliki oleh setiap perusahaan atau lembaga.

Dimana Company Profile, selain sebagai aset perusahaan juga berfungsi sebagai tanda/identitas dari perusahaan dalam menjalin kerjasama/ relasi yang baik dengan perusahaan/lembaga/ instansi terkait lainnya. Secara umum Company Profile dibuat dalam bentuk buku yang ditata secara baik dengan menggunakan unsur desain 
komunikasi visual dengan menggunakan perpaduan unsur bentuk, warna, tipografi serta elemen-elemen estetis pendukung lainnya yang tersusun dalam sebuah tatanan komposisi yang dinamis.

\section{PEMBAHASAN}

\section{Informasi Produk}

Telepon merupakan fasilitas yang sangat dibutuhkan dalam dunia usaha maupun untuk komunikasi di rumah. Masalah yang sering dihadapi adalah ketika biaya penggunaan telepon tidak terkontrol sehingga terjadinya pembengkakan biaya yang harus dikeluarkan setiap bulan. Dengan menggunakan Electronic Billing Telephone, masalah ini dapat diatasi dengan membatasi jumlah maksimal pengeluaran perbulan serta proteksi terhadap pemakai dengan menggunakan password. Setiap pemakai juga dapat dibatasi jumlah pengeluaran perbulannya. Dengan demikian pembengkakan biaya telepon dapat dihindari serta pengeluaran setiap pemakai dapat diketahui.

Spesifikasi Teknis

Model : Electronic Billing Telephone

Spesial feature : Tanpa sumber listrik PLN (menggunakan arus jaringan telepon

Tipe Panggilan : DTMF

Tampilan $\quad$ :Liquid Crystal (LCD) DTSN 32 karakter, 2 baris

Dimensi $\quad: \pm 12.5 \mathrm{~cm} \times 8 \mathrm{~cm} \times 3.5 \mathrm{~cm}$

Berat $\quad: \pm 650 \mathrm{gr}$

\section{Posisi Pasar (Market Positioning)}

Produk ini merupakan produk yang penting dalam pembatasan pulsa telephone dan monitoring pemakaian pulsa. Dengan dibutuhkannya produk ini oleh pengguna telepon dan dengan jumlah pasar pengguna telepon yang luas, maka produk ini mempunyai target pasar yang jelas. Produk Electronic Billing Telephone ini berada diatas tingkat Produk Billing Telephone lainnya karena produk ini dilengkapi dengan fitur utama yang merupakan jawaban dari kebutuhan urgent bagi penggunanya atas produk yang telah hadir tetapi belum lengkap dan masih jarang terdapat dipasar. 
PT. Inovasi Multi Teknologi akan bekerjasama dengan sejumlah distributor yang membeli Produk Electronic Billing Telephone dengan harga dasar pabrik. Distributor diberi kebebasan untuk menetapkan pengecer dengan harga di tingkat pengecer tidak lebih dari Rp 750.000 per unit produk. Metode pemasaran yang akan dilakukan PT Inovasi Multi Teknologi adalah membuat jalur distribusi dan agen - agen serta dengan metode iklan melalui media cetak dan selebaran serta poster yang ditempatkan pada tempat strategis yang berhubungan dengan telekomunikasi. Informasi yang ditekankan adalah penghematan pulsa telepon, kemajuan teknologi dan keunggulan inovasi. Wilayah pemasaran yang menjadi target pasar Electronics Billing Telephone adalah seluruh wilayah Indonesia.

\section{Kondisi Pesaing}

Kompetitor yang ada saat ini cukup banyak, baik dari segi kualitas dan fasilitas. Untuk kualitas dan harga dari kompetitor cukup berimbang dengan PT. Inovasi Multi Teknologi, dimana konsentrasi pasarnya juga di wilayah Jakarta, Bogor, Depok, Tangerang, Bekasi dan sekitarnya. Sistem promosi yang dilakukan kompetitor hampir sama dengan PT. Inovasi Multi Teknologi, dengan cara mengadakan pameran serta dengan adanya media cetak dan informasi seperti umbul-umbul, brosur atau spanduk.

PT. Inovasi Multi Teknologi membuat suatu terobosan dari segi kualitas, kuantitas dan biaya yang dapat terjangkau oleh kalangan ekonomi menengah kebawah serta fasilitas yang memadai. Sehingga calon konsumen tertarik untuk menjadi konsumen Inovasi Multi Teknologi.

Dengan perkembangan ditahun 2009, kompetitor-kompetitor dari PT. Inovasi Multi Teknologi selalu memiliki konsep tersendiri diantaranya : alat yang minimalis, memberikan kualitas dan kuantitas yang baik, harga yang terjangkau dan lain-lain. PT. Inovasi Multi Teknologi juga mempunyai konsep atau keidentikan yaitu menghidupkan konsep alat yang canggih, yang memiliki kemampuan dapat menghemat biaya tagihan sekecil mungkin. Adapun pesaing-pesaing menurut manajemen PT. Inovasi Multi Teknologi diantaranya perusahaan-perusahaan yang menghasilkan produk yang memiliki fungsi sama seperti EBT (Electronic Billing Telephone).

Berikut adalah beberapa pesaing PT. Inovasi Multi Teknologi : 
Tabel 1 Tabel Pesaing

\begin{tabular}{|l|l|l|}
\hline \multicolumn{1}{|c|}{ Pesaing } & \multicolumn{1}{|c|}{ Kelebihan } & \multicolumn{1}{c|}{ Kekurangan } \\
\hline Syntetist & $\begin{array}{l}\text { Lebih hemat hingga } 4 \%-87 \% \\
\text { Bila dibandingkan dengan tarif } \\
\text { PSTN yang berlaku }\end{array}$ & $\begin{array}{l}\text { Masih lemahnya sistem yang } \\
\text { ada pada alat }\end{array}$ \\
\hline SatElite Indocom & $\begin{array}{l}\text { Gratis masa percobaan selama 1 } \\
\text { bulan pertama. }\end{array}$ & $\begin{array}{l}\text { Alat Satelite yang masih } \\
\text { kurang stabil, seringnya terjadi } \\
\text { kerusakan pada alat. }\end{array}$ \\
\hline Quantum & $\begin{array}{l}\text { Lebih hemat, alat yang sudah } \\
\text { canggih. }\end{array}$ & $\begin{array}{l}\text { Konsumen harus membeli alat } \\
\text { penghemat biaya telepon } \\
\text { tersebut. }\end{array}$ \\
\hline
\end{tabular}

\section{Potensial Market}

Media promosi dalam bentuk buku company profile ini ditujukan untuk memberikan suatu informasi lengkap dan spesifik agar konsumen, relasi bisnis maupun masyarakat lebih mengetahui tentang profil PT. Inovasi Multi Teknologi mulai dari sejarah, produk, dan fasilitas.

Dalam hal ini, subjek atau sasaran yang dituju adalah konsumen atau relasi bisnis yang tagihan biaya teleponnya di atas 1 juta rupiah per bulan yaitu dengan cara mempromosikan alat EBT beserta fungsi danfeature yang dimiliki oleh alat tersebut. Yaitu dengan mengikuti berbagai pameran, promosi melalui majalah, serta seminar.

Jika ditinjau dari tujuan promosi ini adalah untuk menarik minat konsumen, relasi bisnis atau masyarakat agar dapat mengenal profil PT. Inovasi Multi Teknologi, lalu memahaminya dan berubah sikap, menyukai, yakin, kemudian akhirnya menjadi customer PT. Inovasi Multi Teknologi.Hal ini, dapat meningkatkan jumlah permintaan akan suatu media informasi dan promosi PT. Inovasi Multi Teknologi untuk memperkenalkan dan memberi pemahaman tentang profil PT. Inovasi Multi Teknologi kepada consumen, calon pelanggan baru, relasi dan masyarakat.

Oleh sebab itu, divisi marketing menginformasikan pada tahun 2009 jumlah penerimaan pelanggan baru mencapai 600 pelanggan dengan pemasangan alat Electronic Billing Telephone sebanyak 600 unit, namun untuk tahun 2010 divisi marketing mentargetkan jumlah penerimaan pelanggan baru dan pemasangan alat EBT mencapai 800 hingga 900 unit. 


\section{Market Segmentation}

Segmentasi market dari perusahaan ini adalah :

Geografi : Wilayah JABODETABEK, Jawa Tengah dan DI Yogyakarta, Jawa Timur, Sumatra, Bandung dan Bali.

Demografi : Perusahaan Swasta dan Perusahaan Negara Menengah ke atas. Psikografi :Perusahaan yang memiliki tagihan biaya telepon Satu Juta Rupiah ke atas per bulan.

\section{Market Objective (Tujuan Pemasaran)}

Dalam memberikan media informasi dan promosi tentang profil PT. Inovasi Multi Teknologi kepada konsumen (calon pelanggan baru, relasi maupun masyarakat) divisi marketing menambah media komunikasi sarana promosi, yaitu dengan media buku company profil karena media informasi promosi yang digunakan sebelumnya (brosur) masih kurang lengkap, oleh sebab itu media buku company profil dirancang secara detail dan menarik agar dapat meningkatkan jumlah calon pelanggan baru di tahun 2010, yaitu sesuai target dari divisi marketing sebanyak 800 Customer hingga 900 Customer baru atau 800 hingga 900 unit alat EBT yang terpasang dan menjadi customer PT. Inovasi Multi Teknologi..

\section{Market Strategi (Strategi Pemasaran)}

PT. Inovasi Multi Teknologi adalah salah satu perusahaan yang bergerak dibidang jasa dan manufaktur. Produk yang dihasilkan adalah Electronic Billing Telephone, yaitu sebuah produk pengontrol pemakaian telepon yang memberikan solusi akan efisiensi dan otomatisasi secara elektronik, sehingga dapat melakukan penghematan dan menghindari penyalahgunaan hingga pembatasan maksimal untuk pembayaran telepon.

Strategi pemasaran yang digunakan oleh PT. Inovasi Multi Teknologi adalah dengan menghasilkan produk yang baik, mudah digunakan, memiliki fungsi yang dapat menghemat pemakaian biaya telepon serta melakukan berbagai keuntungan untuk konsumen, distributor, atau perusahaan baik pengguna langsung maupun tidak langsung.

Buku company profil PT. Inovasi Multi Teknlogi merupakan bagian dari strategi media promosi yang diterapkan oleh divisi mareketing. Adapun kegiatan- kegiatan program promosi PT. Inovasi Multi Teknlogi, diantaranya :

1. Melalui jalur distributor

Distributor membeli dengan sistem beli putus harga yang ditetapkan adalah sebagai berikut:

1. Jumlah produk $<10 \quad \operatorname{Rp} 525.000$ 
2. Jumlah produk $10-24 \quad \operatorname{Rp} 515.000$

3. Jumlah produk $25-50 \quad \mathrm{Rp} 500.000$

4. Jumlah produk $51-99 \quad \operatorname{Rp} 475.000$

5. Jumlah produk $>100 \quad \operatorname{Rp} 465.000$

2. Melalui marketing aktif (door to door)

Masing masing marketing ditargetkan memperoleh penjualan minimal 30 unit dalam 1 bulan dengan ketentuan fee marketing, Jumlah penjualan minimal 30 produk, harga dari perusahaan sebesar 320.000 , perkiraan harga jual pasar antara 350.000 -375.000 , gaji marketing sebesar $600.000 /$ bln. Jika person berhasil menjual diatas 30 produk maka harga dari perusahaan sebesar Rp 300.000

3. Melalui marketing pasif (buka stand pada mall ternama)

Srategi yang dilakukan dengan membuka stand pada mall, mempekerjakan karyawan dengan gaji 750.000/bln dengan bonus marketing per produk 5.000,-

\section{Software yang Digunakan}

Dalam Konsep media informasi dan promosi software yang digunakan adalah Adobe Photoshop Cs2 dan Illustrator Cs2 .

Definisi Software Yang Digunakan

a. Adobe Photoshop Cs2 adalah suatu perangkat lunak canggih yang dapat kita gunakan membuat, menyunting dan menipulasi tampilan termasuk mengoreksi dan memberi efek tampilan atas sebuah gambar atau photo, hasil dari program ini merupakan sebuah gambar/image di dalam komputer grafis terbagi menjadi 2 kelompok yaitu gambar Bitmap dan gambar Vektor.

b. Adobe Illustrator Cs 2 adalah program grafis berbasis vektor yang paling tangguh dan populer, karena fasilitas-fasilitas di dalamnya dapat digunakan untuk membentuk objek secara tiga dimensi, sehingga hasil yang diperoleh menyerupai objek yang sebenarnya.

\section{Tujuan Media}

Tujuan perancangan media Company Profile sebagai salah satu sarana untuk mempromosikan aset perusahaan kepada masyarakat luas, pelaku bisnis khususnya perusahaan atau relasi yang ingin melakukan kerjasama dengan PT. Inovasi Multi Teknologi.Dengan adanya media Company Profile diharapkan dapat meningkatkan 
citra perusahaan serta dapat menumbuhkan kepercayaan kepada kalangan masyarakat.

\section{Strategi Media}

Sebelum melakukan proses desain, penulis terlebih dahulu merumuskan strategi media. Adapun sasaran dari perancangan media promosi Company Profile yang dirancang untuk memenuhi 3 (tiga) aspek sasaran yaitu :

Geografi : Wilayah JABODETABEK, Jawa Tengah dan DI Yogyakarta, Jawa Timur, Sumatra, Bandung dan Bali.

Demografi : Perusahaan Swasta dan Perusahaan Negara Menengah ke atas.

Psikografi :Perusahaan yang memiliki tagihan biaya telepon Satu Juta Rupiah ke atas per bulan.

Agar tercapainya tingkat efektivitas program promosi PT. Inovasi Multi Teknologi, bahwa perancangan media promosi ini diharapkan dapat menunjang kelancaran penjualan alat Electronic Billing Telephone.

\section{Program Media}

Media sarana penunjang promosi tentang profil PT. Inovasi Multi Teknologi dirancang dengan bentuk booklet, serta rencana dipergunakannya mulai semester II (dua) tahun 2010 dan dalam jangka panjang karena rancangan penulis harus menyesuaikan dengan kondisi program promosi yang ada pada PT. Inovasi Multi Teknologi.

\section{Tujuan Kreatif}

Perancangan media penunjang promosi berupa buku Company Profile pada PT. Inovasi Multi Teknologi supaya menarik secara visual, penulis menampilkan profil perusahaan melalui gambar alat EBT dan spesifikasinya, gambar bagian manajemen perusahaan, keunggulan produk, model usaha, peta wilayah pemasaran, gambar kegiatan produksi, kegiatan dalam mengikuti pameran, kerjasama dengan mitra usaha diolah dan dirancang sedemikian rupa sehingga hasil perancangan dapat menarik bagi pembaca dan mendapatkan perhatian dari pelaku bisnis dan pelanggan agar dapat bekerjasama dengan PT. Inovasi Multi Teknologi selain itu juga bertujuan untuk mendapatkan konsumen baru dalam mencapai target seperti yang diinginkan oleh perusahaan. Perancangan media diharapkan dapat meningkatkan citra perusahaan di mata masyarakat. Adapun tujuan utama dari perancangan media Company Profile yaitu :

a. Dapat meyakinkan calon konsumen khususnya pelaku bisnis yang ingin melakukan kerjasama dengan PT. Inovasi Multi Teknologi. 
b. Dapat menciptakan image yang baik serta menyampaikan kualitas produk yang dihasilkan oleh PT. Inovasi Multi Teknologi.

c. Menyampaikan tentang fungsi kegunaan dan keunggulan produk EBT.

\section{Strategi Kreatif}

Dalam perencanaan sarana media penunjang promosi dirancang sebuah media promosi Company Profile, mengenai hal yang berhubungan dengan kualitas akan disampaikan melalui gambar alat EBT. beserta spesifikasinya. Agar tujuan program promosi dapat tercapai harus bisa menyampaikan informasi yang tepat dan menarik kepada konsumen, selain dari itu media yang dirancang harus bisa efektif dalam penggunaannya. Selain media tersebut berisi tentang seluruh profil yang ada di perusahaan, media tersebut sekaligus sebagai sarana penunjang promosi dan dapat meningkatkan citra atau image PT. Inovasi Multi Teknologi.

\section{Tujuan Visual}

Untuk memenuhi nilai-nilai efektifitas dan mempunyai daya tarik terhadap konsumen. Media utama dan media penunjang dirancang dengan pewarnaan dan teknik yang terdapat pada aplikasi-aplikasi program komputer. Nilai-nilai grafis akan selalu tampil guna menunjang daya tarik dalam pemakaiannya.

Adapun suasana yang ingin disampaikan penulis dengan menampilkan desain komunikasi visual media promosi dengan kesan modern dan minimalis dengan perpaduan antara tata letak (layout), warna dan tipografi yang dinamis.

Citra yang ingin penulis sampaikan dalam desain ini menggambarkan sebuah perusahaan yang mempunyai keunggulan dalam kualitas produk yang dihasilkan.

\section{Strategi Visual}

Dalam hal ini media promosi yang dirancang akan ditampilkan secara komunikatif, modern, dan minimalis. Adapun strategi visual yang ingin disampaikan penulis adalah dengan pendekatan secara emosional, yang mengambarkan sebuah perusahaan yang bergerak di bidang manufacting PT. Inovasi Multi Teknologi di harapkan dapat meyakinkan relasi bisnis atau calon serta dapat menciptakan citra perusahaan. Dalam hal ini penyajian grafisnya secara sederhana agar mudah di pahami oleh pembaca.

\section{Penulisan Naskah}

Agar penyampaian pesan bisa tepat sasaran, maka pesan media dibuat secara terurut dengan alur yang benar, yaitu: 
1. Penulisan judul (Headline) : Slogan dari cover adalah SOLUSI HEMAT UNTUK KOMUNIKASI ANDA, COMPANY PROFILE, logo PT. IMT.

2. Sub-sub halaman berikutnya disampaikan sesuai dengan susunan isi Company Profile.

Dalam pembuatan suatu media promosi Company Profile agar media tersebut terlihat menarik dan tidak terlihat kaku tampilan grafisnya, maka rancangan media tersebut mengikuti kaidah-kaidah sebagai berikut:

1. Tonalitas warna yang dipilih diantaranya
a) Warna Biru
Respon psikologisnya yaitu, kepercayaan dan teknologi.
b) Warna Kuning
Respon psikologisnya yaitu, optimis, kejayaan, penuh harapan.
c) Warna Merah
Respon psikologisnya yaitu, power dan energy.
d) Warna Putih
Respon psikologisnya yaitu, ketepatan.
e) Warna Hitam
Respon psikologisnya yaitu, power, kecanggihan.
f) Warna Hijau
Respon psikologinya yaitu keberuntungan dan pembaharuan.
g) Warna Coklat
Respon psikologinya yaitu kenyamanan dan daya tahan.

2. Jenis huruf yang relevan adalah:

Jenis huruf yang dipakai dalam perancangan diantaranya jenis huruf yang sesuai dengan desain yang dibuat yaitu : Perpetua Titling MT, Arial,Arial Black. Myriad Roman, Times New Roman PS MT Bold.

3. Tata letak atau layout yang digunakan adalah

Tata letak disesuaikan dengan media elemen-elemen yang terdapat di rancangan media Company Profile dengan menata atau menyatukan unsur-unsur komunikasi visual mulai dari teks, gambar dan warna agar menjadi media komunikasi visual yang komunikatif dan dapat menarik perhatian calon konsumen.

4. Gaya penampilan grafis

Gaya tampilan visual secara grafis ditampilkan kesan modern dan minimalis yang komunikatif, dimaksudkan agar audience dapat lebih mudah mengetahui pesan media yang disampaikan. 


\section{Layout Kasar}

Tahap awal dalam proses desain, terlebih dahulu harus membuat layout kasar, adapun yang dimaksud dengan layout kasar adalah gambar kerja untuk memperlihatkan komposisi tata letak naskah, gambar yang akan dibuat, biasanya pada layout kasar ini dibuat hitam putih berupa coretan kasar atau sketsa dengan menggunakan pensil gambar yang dibuat secara manual.

Pada tahap ini penulis akan membahas proses layout kasar yang merupakan ide kreatif mengenai susunan atau tata letak unsur-unsur rancangan media dari penulis.

\section{Layout kasar Cover Depan dan Cover Belakang}

Desain halaman cover depan menampilkan logo, motto dan alamat perusahaan PT. Inovasi Multi Teknologi, tujuannya apabila ada konsumen (calon pelanggan, relasi dan masyarakat) ingin mengetahui lebih lanjut mengenai profil PT. Inovasi Multi Teknologi.

Sedangkan cover belakang menampilkan foto-foto kegiatan perusahaan, Electronic Billing Telephone dan logo perusahaan. Berikut ini adalah layout kasar halaman cover depan dan belakang yang dibuat secara manual dengan menggunakan goresan pensil gambar.

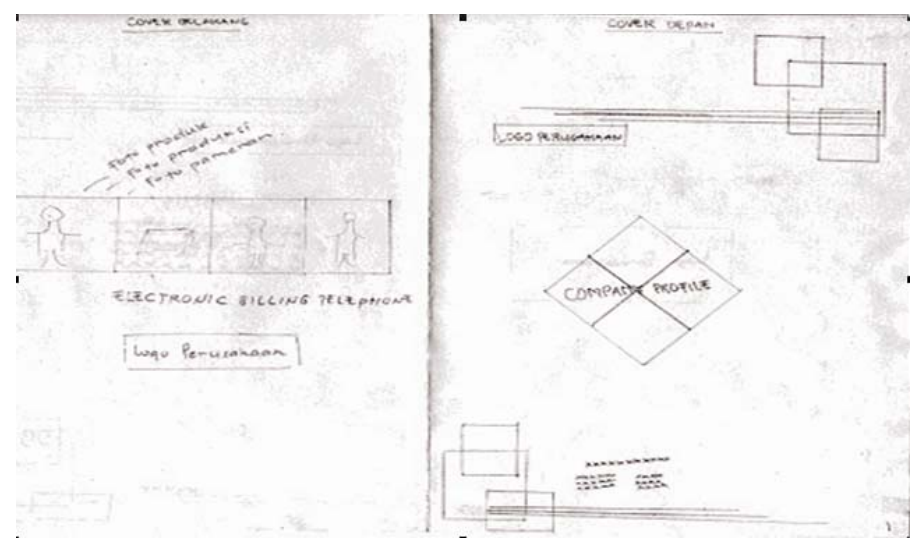

Gambar 1

Layout kasar cover depan dan cover belakang

\section{Layout Kasar Logo dan Model Bisnis}

Desain halaman ini hanya menampilkan logo perusahaan saja. Sedangkan halaman model bisnis berfungsi untuk menginformasikan kepada konsumen, distributor dan produsen tentang sistem kerja PT. Inovasi Multi Teknologi. 


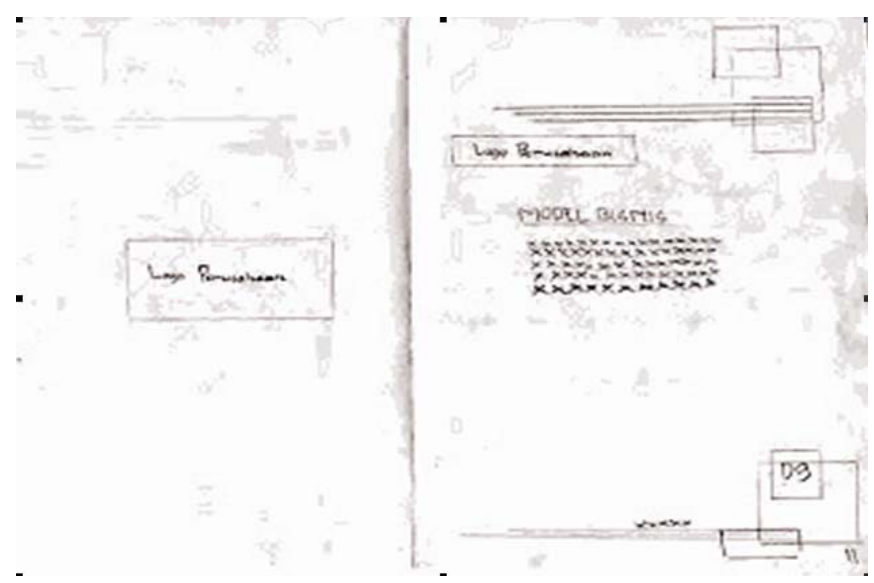

Gambar 2

Layout kasar logo dan model bisnis

\section{Layout Kasar Daftar Isi dan Lingkup Usaha}

Pada halaman daftar isi ini akan ditampilkan isi dari buku Company Profile PT.Inovasi Multi Teknologi, secara menyeluruh mulai dari profil perusahaan sampai model bisnis. Lingkup Usaha terdiri dari Electronic Perusahaan, IT Production, Pemasaran, Fasilitas dan badan hukum perusahaan.

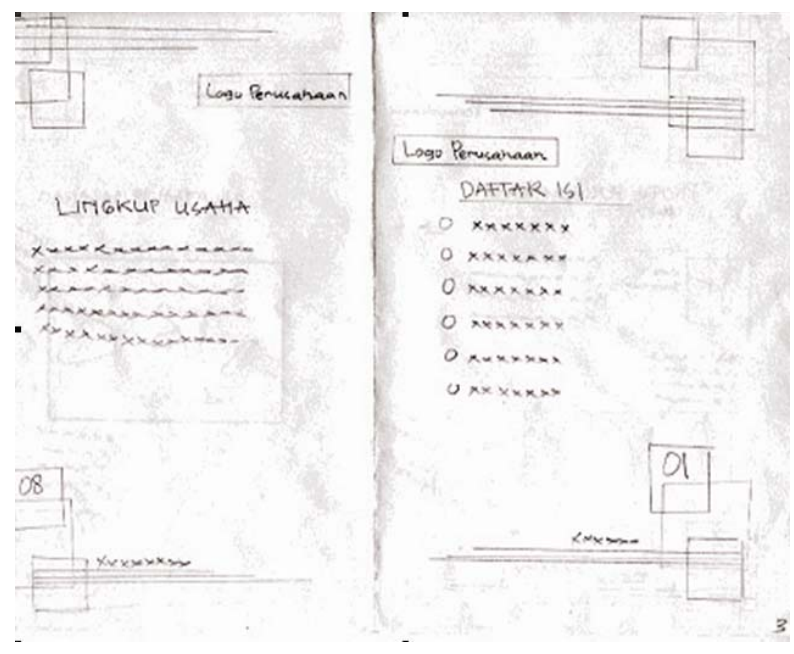

Gambar 3.

Layout kasar daftar isi dan lingkup usaha 


\section{Layout Kasar Profil Perusahaan dan Wilayah Pemasaran}

Pada halaman ini menginformasikan profil perusahaan yaitu tentang sejarah singkat awal bedirinya perusahaan PT. Inovasi Multi Teknologi. Dan menampilkan foto direktur serta beberapa foto kegiatan promosi produk Electronic Billing Telephone.

Wilayah pemasaran menampilkan beberapa daerah atau provinsi yang merupakan wilayah pemasaran produk Electronic Billing Telephone. Berikut layout kasar profil perusahaan dan wilayah pemasaran :

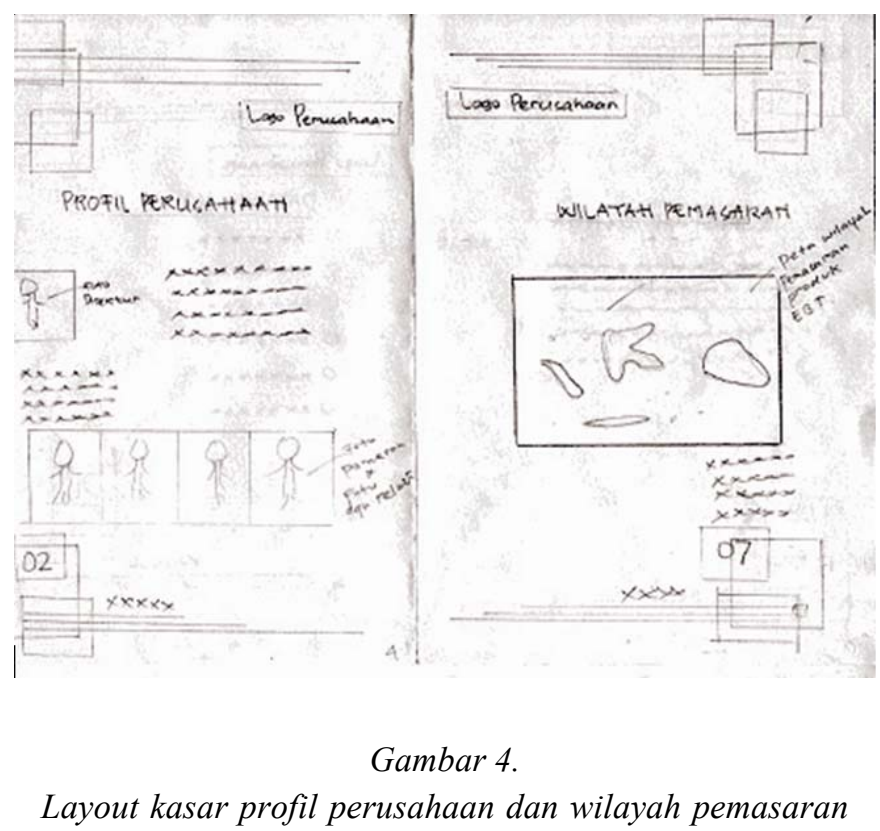

\section{Layout Kasar Visi, Misi, Motto Perusahaan dan Pemasaran Produk}

Background halaman desain layout visi, misi dan motto perusahaan ini berwarna biru dengan gradasi warna putih, dan menampilkan foto menara.

Halaman layout pemasaran produk menginformasikan tentang kejelasan pasar yang dituju perusahaan, ukuran pasar, pertumbuhan pasar dan informasi lainnya yang berkaitan dengan posisi atau keadaan produk Electronic Billing Telephone di masyarakat dan market. Berikut layout kasar profil perusahaan dan wilayah pemasaran : 


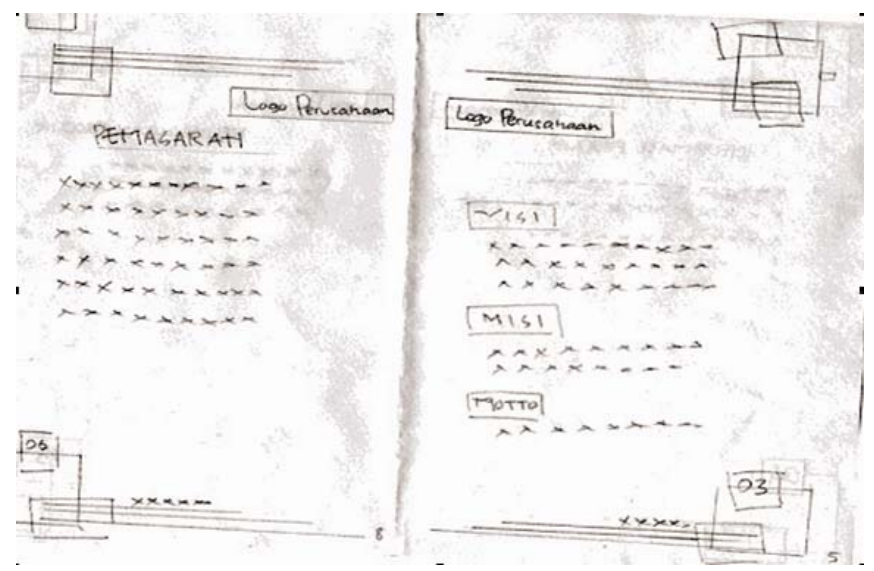

Gambar 5.

Layout kasar visi, misi, motto perusahaan dan pemasaran produk

\section{Layout Kasar Informasi Produk dan Keunggulan Produk}

Layout ini ditujukan untuk menginformasikan spesisifikasi, fungsi fitur, kelengkapan produk dan gambar produk. Sedangkan desain layout kasar keunggulan produk ini menginformasikan tentang kelebihan produk Electronic Billing Telephone secara terperinci.

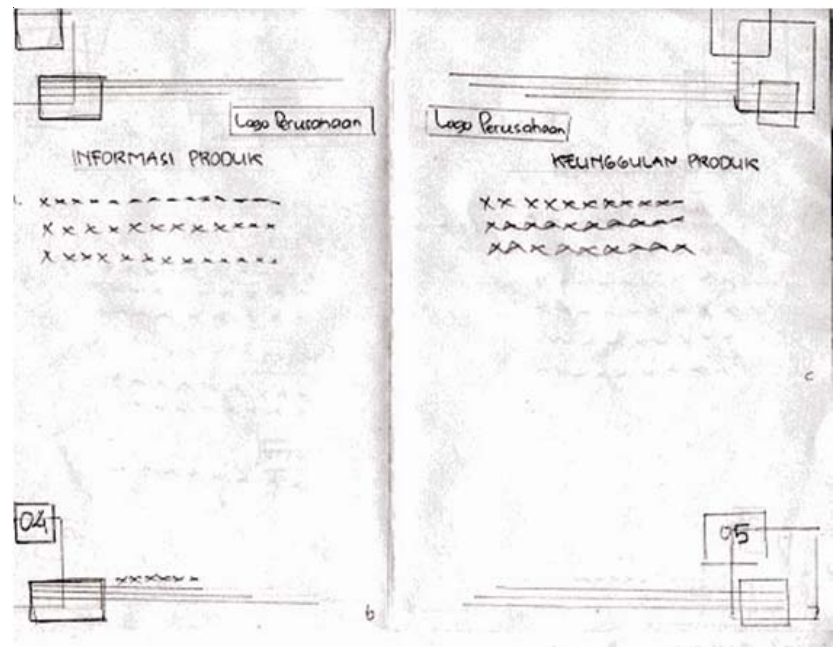

Gambar 6.

Layout kasar informasi produk dan keunggulan produk 


\section{Final Artwork}

Artwork adalah merupakan gambar kerja final yang telah melewati beberapa proses sebelumnya yaitu layout kasar dan layout komprehensif. Pada proses ini naskah serta tata letak gambar merupakan proses akhir sebelum dilakukan proses cetak untuk media buku Company Profile telah disempurnakan dengan beberapa kali revisi selama proses desain.

\section{Final Cover Depan dan Cover Belakang}

Di bawah ini adalah layout front cover yang dibuat setelah mengalami beberapa revisi perubahan, diantaranya : desain cover depan menggunakan background warna biru yang menciptakan kesan teknologi dan merupakan image dari PT. Inovasi Multi Teknologi. Cover depan ini juga terdapat logo dan motto dari PT. Inovasi Multi Teknologi yang menggunakan jenis huruf Perpetua Titling MT Bold dan Arial Black dan Myriad untuk tulisan Company Profile, dengan diberi sentuhan efek gradient dan stroke serta menggunakan ukuran kertas 43 x $29.7 \mathrm{~cm}$.

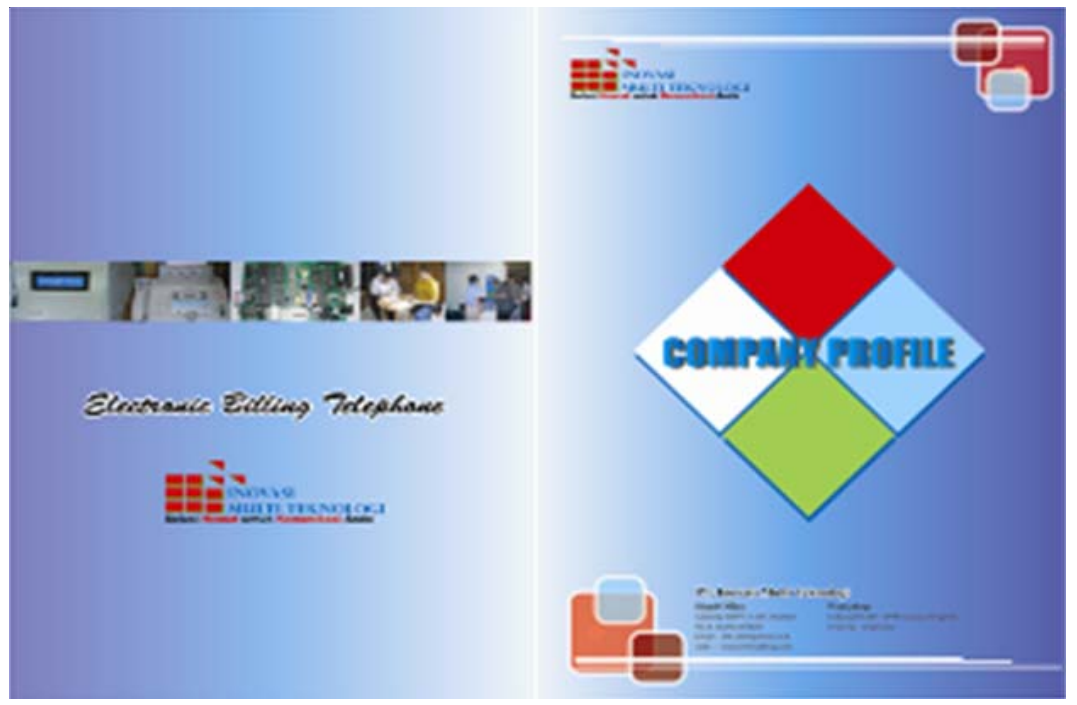

Gambar 7.

Final Artwork Cover Depan dan Cover Belakang

\section{Final Logo Perusahaan dan Model Bisnis}

Desain ini menampilkan halaman logo perusahaan dan model bisnis. Background tampilan halaman berwarna biru, dan menggunakan jenis huruf Stencil Std Bold dan Arial. 


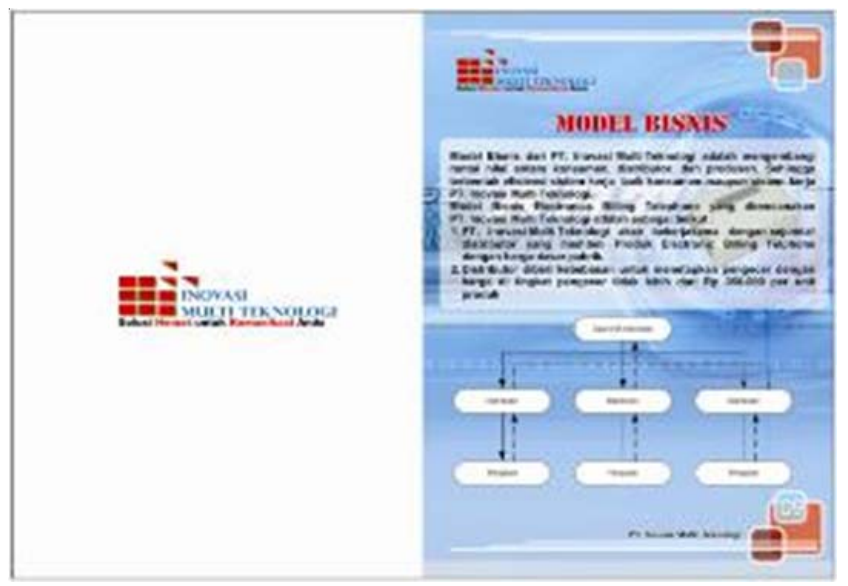

Gambar 8.

Final Artwork Logo Perusahaan dan Model Bisnis

\section{Final Daftar Isi dan Lingkup Usaha}

Desain halaman daftar isi dan Lingkup Usaha ini akan menjelaskan mengenai isi yang ada di buku Company Profile PT. Inovasi Multi Teknologi agar konsumen (calon pelanggan baru, relasi maupun masyarakat) lebih cepat mengetahui halaman informasi yang dibutuhkan tanpa harus mencari lagi serta menjelaskan tentang lingkup usaha. Background yang digunakan warna biru, gradasi putih. Jenis huruf pada daftar isi yaitu menggunakan Stencil Std Bold dan Arial.

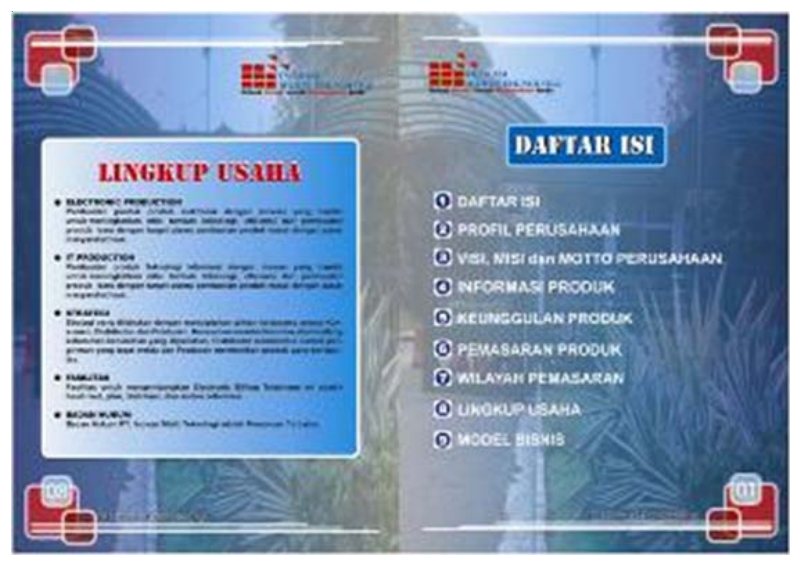

Gambar 9.

Final Artwork Daftar Isi dan Lingkup Usaha 


\section{Final Artwork Profil Perusahaan dan Wilayah Pemasaran}

Desain ini merupakan halaman pertama setelah daftar isi yang berisikan profil PT. Inovasi Multi Teknologi. Menggunakan jenis huruf Stencil Std Bold dan arial. Background menggunakan warna biru gradasi putih serta menampilkan foto kegiatan saat mengikuti pameran dan foto direktur PT. Inovasi Multi Teknologi.

Desain halaman wilayah pemasaran menggunakan background warna biru dan gradasi putih, menggunakan huruf Stencil Std Bold dan arial. Desain ini menampilkan peta wilayah Indonesia untuk memberikan informasi provinsi-provinsi pemasaran produk Electronic Billing Telephone.
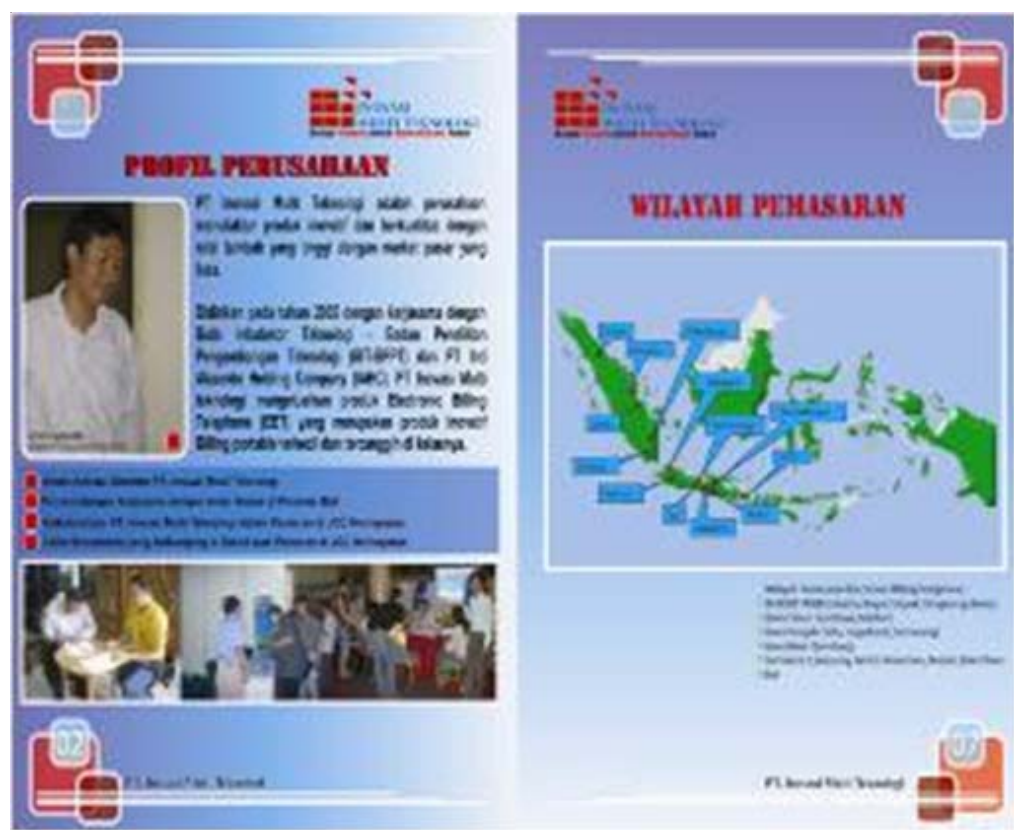

Gambar 10.

Final Artwork Profil Perusahaan dan Wilayah Pemasaran

\section{Final Artwork Visi, Misi, Motto Perusahaan dan Pemasaran Produk}

Yang sama dengan halaman lainnya yaitu warna biru dan gradasi putih yang merupakan image PT. Inovasi Multi Teknologi, serta diberi sentuhan background foto menara. Menggunakan huruh Arial dan Arial Bold. Halaman pemasaran ini menggunakan background warna biru dan gradasi putih, menggunakan huruf Stencil Std Bold untuk judul dan arial bold untuk sub judul dan isi. 

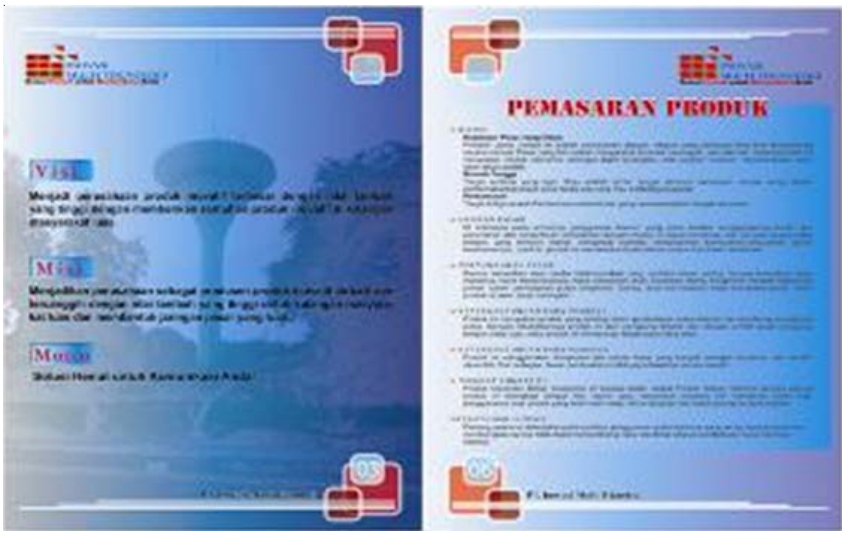

Gambar 11.

Final Artwork Visi, Misi dan Motto serta Pemasaran Produk

\section{Final Artwork Informasi Produk dan Keunggulan Produk}

Untuk desain halaman ini berisikan mengenai informasi produk, spesifikasi, kelengkapan produk dan fungsi fitur serta menampilkan foto-foto produk. Menggunakan huruf Stencil Std Bold dan arial, background berwarna biru dengan gradasi putih.

Untuk tampilan halaman keunggulan produk menggunakan background yang sama dengan halam lainnya yaitu berwarna biru dan gradasi putih. Dan menampilkan foto-foto kegiatan produksi alat Electronic Billing Telephone. Menggunakan huruf Stencil Std Bold dan arial.

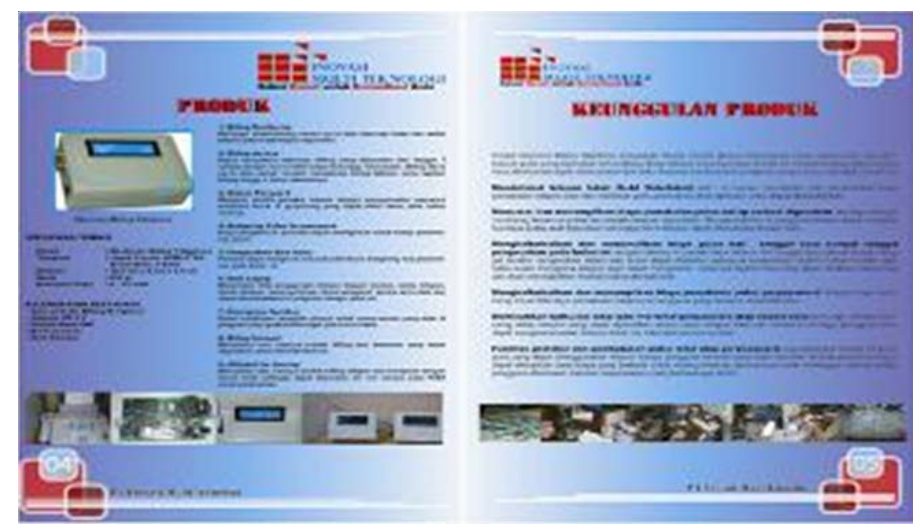

Gambar 12.

Final Artwork Informasi Produk dan Keunggulan Produk 


\section{KESIMPULAN}

Perancangan media promosi untuk menunjang penjualan dibidang pemasaran alat EBT (Electronic Billing Telephone) tentunya harus ada media pendukung dan ciri yang melambangkan identitas. Media promosi dan informasi yang efektif untuk memperkenalkan kapasitas dan kualitas perusahaan adalah Media promosi berupa buku Company Profile, media promosi buku Company Profile ini sangat besar pengaruhnya dalam menyampaikan pesan dan informasi yang dibutuhkan oleh masyarakat dan juga relasi bisnis perusahaan, khususnya untuk PT. Inovasi Multi Teknologi. Disini media promosi Company Profile dibuat untuk mendukung pemasaran atau promosi, untuk meningkatkan suatu image atau citra dari perusahaan untuk menjalin kerja sama dengan relasi perusahaan, lembaga dan instansi terkait lainnya. Company Profile tersebut sebagai aset perusahaan yang dipegang dan dimiliki oleh setiap perusahaan atau lembaga. Dimana Company Profile, selain sebagai aset perusahaan juga berfungsi sebagai tanda atau identitas dari perusahaan dalam menjalin kerjasama/relasi yang baik dengan perusahaan/lembaga/instansi terkait lainnya.

Merancang media Company Profile yang mempunyai nilai daya tarik, meningkatkan image perusahaan dan sekaligus dapat menunjang program promosi adalah dengan merancang media promosi yang mampu menampilkan citra atau image perusahaan, dan memiliki aspek tampilan, citra maupun unsur-unsur visual yang terstruktur. Menciptakan sebuah media informasi dan promosi yang sesuai dengan citra atau image perusahaan adalah dengan memberikan sentuhan dari ciri khas dari perusahaan tersebut, misalnya identitas warna perusahaan, logo perusahaan, motto perusahaan dan lain sebagainya.

\section{DAFTAR PUSTAKA}

1. Hendratman, Hendi (2006). Tips n Trix Computer Graphics Design. Informatika,Bandung.

2. Jogiyanto,Hartono (1999), Pengenalan komputer, Dasar Ilmu Komputer, Pemrograman, Sistem Informasi, dan integrasi buatan, Andi Offset, Yogyakarta.

3. Susanto Mikke, (2002), Diksi Seni Rupa, Yogyakarta.

4. Saputra, Jayan. (2006). Photoshop CS2 untuk Orang Awam. Maxikom, Palembang.

5. Tjiptono, Fandi. (2005). Strategi Pemasaran. Andi, Yogyakarta.

6. Wikipedia Indonesia, Ensiklopedia Bebas Berbahasa Indonesia, 11 Desember 2006. 